\title{
Silencing of Livin inhibits tumorigenesis and metastasis via VEGF and MMPs pathway in lung cancer
}

\author{
XIAN LIN ${ }^{1}$, HONG-RU LI ${ }^{1}$, XIAO-FEN LIN ${ }^{2}$, MEI-E YU ${ }^{1}$, XUN-WEI TU ${ }^{1}$, \\ ZHI-DAN HUA ${ }^{1}$, MING LIN ${ }^{1}$, NENG-LUAN XU ${ }^{1}$, LI-LI HAN ${ }^{3}$ and YU-SHENG CHEN ${ }^{1}$ \\ ${ }^{1}$ Department of Respiratory Medicine, Fujian Provincial Hospital, Fujian Provincial Clinical Medical College of \\ Fujian Medical University, Fuzhou 350001; ${ }^{2}$ Department of Respiratory Medicine, Fujian Zhangzhou First Hospital, \\ Clinical Medical College of Fujian Medical University, Zhangzhou 363000; ${ }^{3}$ Cardiovascular Key Laboratory of \\ Fujian Province, Fujian Provincial Hospital, Fujian Provincial Clinical Medical College \\ of Fujian Medical University, Fuzhou 350001, P.R. China
}

Received February 27, 2015; Accepted May 8, 2015

DOI: 10.3892/ijo.2015.3058

\begin{abstract}
Livin, an inhibitor of apoptosis protein (IAP), is overexpressed in various cancers and decreases tumor sensitivity to chemotherapy and radiotherapy. However, the effect of Livin on lung adenocarcinoma metastasis and the specific mechanism involved remain unclear. RNAi technology was used to stably silence Livin in A549 cells in the present study. The effect of Livin on tumor growth and invasion was investigated in lung cancer cells in vitro and animal models were established to determine the anti-metastasis ability of Livin silencing in vivo. The results indicated that Livin knock-down suppressed cell proliferation and inhibited cell invasion, accompanied by downregulation of VEGF and MMP-2/-9. Silencing of Livin resulted in the prevention of xenograft tumor formation. Seventy-five immunodeficient male BALB/C nude mice were randomly divided into three groups, the relative ratio of the areas with pulmonary nodules in the experimental group decreased from $46.71 \pm 7.27 \%$ to $11.07 \pm 2.94 \%$ compared with the negative control group $(\mathrm{P}<0.001)$, indicating the interaction between Livin, VEGF and MMPs. The xenograft tumor model of intravenous injection of tumor cells were successfully established and applied for the analysis of lung cancer tumorigenesis and metastasis in a time-dependent manner for the first time. Based on the reliable and reproducible animal
\end{abstract}

Correspondence to: Professor Yu-Sheng Chen, Department of Respiratory Medicine, Fujian Provincial Hospital, Fujian Provincial Clinical Medical College of Fujian Medical University, No. 134 Dong Jie, Fuzhou, Fujian 350001, P.R. China

E-mail: slyyywb@126.com

Abbreviations: RNAi, RNA interference; ShRNA, small hairpin RNA; VEGF, vascular endothelial growth factor; MMPs, matrix metalloproteinases; mTOR, mechanistic target of rapamycin; ERK1/2, extracellular signal-regulated kinase $1 / 2$; MAPK, mitogen-activated protein kinase

Key words: Livin, lung adenocarcinoma, metastasis, intravenous injection, xenograft tumor model model, our findings indicate that knock-down of Livin inhibits cell growth and invasion through blockade of the VEGF and MMPs pathways in lung cancer cells in vitro, and inhibits tumorigenesis and metastasis of lung cancer in vivo, suggesting that Livin is a promising antitumor target.

\section{Introduction}

Lung cancer, which is characterized by high morbidity and mortality, has become the leading cause of cancer-related death worldwide. Although the number of novel anticancer strategies has increased, the 5-year survival rate for lung cancer remains low, ranging from $9 \%$ to $20 \%$ (1), indicating the limited effectiveness of therapy in recent years. The obstacle in improving the lifespan of lung cancer patients is related to metastasis, which is widely accepted as the most devastating stage of cancer progression, following the dissemination of cancer. During the process of metastasis, tumor cells are required to overcome a series of rate-limiting barriers. As the primary tumor develops vascularization, degradation of the extracellular matrix (ECM) follows, then intravasation, and finally cells arrested in a new organ form micrometastases after extravasating from the circulating blood (2). Therein, the subsequent step that cancer cells extravasated from blood circulation into secondary organ is the most ineffective step in metastatic processes and is suggestive of a promising target.

The metastatic processes involve VEGF, MMPs, the host ECM and several signaling pathways (3). Clinical trials on the inhibition of VEGF and MMPs have shed light on broad development prospects, but are inevitably accompanied by side effect due to low selectivity. Additional evidence suggests that VEGF modulates Livin expression via mTOR signaling (4), as well as MMP-2/9 through the ERK1/2 or Notch pathway $(5,6)$. Moreover, MMPs also mobilize pro-angiogenic factors, for example VEGF, to promote tumor angiogenesis $(7,8)$, and Livin downregulate the expression of VEGF and MMP-2 to inhibit cell growth and invasion through the MAPK signaling (9). Thus, we propose that there are signaling feedback loops between Livin, VEGF, and MMPs in spite of the ambiguous mechanism, and 
synergistic inhibition of VEGF and MMPs triggered by Livin knock-down can elicit tumor regression in lung cancer (9).

Livin, known as an inhibitor of apoptosis (IAP), is selectively overexpressed in specific tumors, and correlates with survival, prognosis, chemotherapeutic and radiotherapeutic resistance (10-12). Many studies have discussed the importance of Livin in the control of invasion of oral squamous cell carcinoma (13), laryngohypopharyngeal cancer (14), breast cancer (15), osteosarcoma (16), prostate cancer (17) and digestive system neoplasms $(9,18,19)$. We demonstrate that knock-down of Livin induces cell cycle arrest at the G0/G1 phases and promote apoptotic death through a caspase-dependent pathway in lung cancer $(20,21)$. Thus, Livin may be an alternative, efficient and safe target in lung cancer therapy, based on the fact that Livin is undetectable in most normally differentiated tissues, with the exception of the placenta, normal testes, spinal cord and lymph nodes (22).

However, few of the studies have evaluated the invasive ability in animal models and shown the function of Livin in lung cancer invasion. Here, we successfully blocked the in vitro invasion and in vivo metastasis of lung adenocarcinoma cells in the animal model by silencing Livin, and demonstrate that Livin affects tumor cell biology through the VEGF and MMPs signaling pathway.

\section{Materials and methods}

Cell culture. The human A549 adenocarcinoma cell line was purchased from American Type Culture Collection (ATCC) and was propagated in RPMI-1640 (HyClone Corp., Logan, UT, USA) medium supplemented with $10 \%$ (v/v) fetal bovine serum (FBS) (HyClone Corp.), $100 \mathrm{U} / \mathrm{ml}$ penicillin and $100 \mathrm{~g} / \mathrm{ml}$ streptomycin, at $37^{\circ} \mathrm{C}$ in a humidified atmosphere of $5 \% \mathrm{CO}_{2}$ and $95 \%$ air.

Construction of lentivectors for specific silencing of Livin expressionand stabletransfection. Shorthairpin RNA(shRNA) consisting of double chains of oligonucleotide with complementary sequences were obtained from Sangon Co. Ltd (Shanghai, China). Based on the Livin sequence (NM_022161.3), LivnshDNA sequences were: 5'-GGAGAGAGGTCCAGTCTGA-3' (sense) and 5'-TCAGACTGGACCTCTCTCCTG-3' (antisense). The pLKD-CMV-G\&PR_U6 plasmid vector (NeuronBiotech Co. Ltd., Shanghai, China) encoded genes for ampicillin and puromycin resistance, and an enhanced green fluorescent protein (eGFP) reporter gene. A293T cells (NeuronBiotech Co. Ltd.) were co-transfected with the recombinant plasmid and packing plasmid, envelope plasmid VSVG, and the pseudoviral particles were collected and the titer was determined. The harvested lentivirus was transfected into A549 cells using Polybrene reagent (Millipore Corp., Billerica, USA). The stably transfected cells were picked out with puromycin, and the green fluorescence intensity was measured by fluorescence microscopy. The cells transfected with vectors carrying Livn-shRNA were defined as the KD group (the experimental group), the cells transfected with vectors as a negative control were defined as the NC group, and the wild-type A549 cells were defined as the $\mathrm{CO}$ group (the blank control group).

Real-time fluorescent quantitative PCR. Total RNAs were extracted using TRIzol reagent (Invitrogen/Life Technologies,
Grand Island, NY, USA) from cells or harvested tissues. cDNA synthesis was performed using reverse transcription reagents (Thermo Scientific, Waltham, MA, USA). According to the manufacturer's instructions, real-time PCR was performed using ViiA 7 (ABI, Carlsbad, USA) sequence detection system with SYBR-Green I Mix (CoWin Biotech Co, Ltd. Beijing, China). The primers for the genes are listed below: Livin sense: 5'-GCTCTGAGGAGTTGCGTCTG-3', antisense: 5'-CACAC TGTGGACAAAGTCTCTT-3'; VEGF sense: 5'-AGGGCAGA ATCATCACGAAGT-3', antisense: 5'-AGGGTCTCGATT GGATGGCA-3'; KDR sense: 5'-GGCCCAATAATCAGAG TGGCA-3', antisense: 5'-CCAGTGTCATTTCCGATCACTT T-3'; MMP2 sense: 5'-TACAGGATCATTGGCTACACAC C-3', antisense: 5'-GGTCACATCGCTCCAGACT-3'; MMP9 sense: 5'-TGTACCGCTATGGTTACACTCG-3', antisense: 5'-GGCAGGGACAGTTGCTTCT-3'; GAPDH sense: 5'-CCA TGGCACCGTCAAGGCTGA-3', antisense: 5'-GGGCCATC CACAGTCTTCTGG-3'. The data are presented as ratios relative to GAPDH levels. Data were analyzed using the comparative Ct method $\left(2^{-\Delta \Delta C t}\right)$.

Western blotting. Cells or tissue were harvested and lysed on ice for $30 \mathrm{~min}$ in buffer consisting of $50 \mathrm{mM}$ Tris $\mathrm{HCl}, \mathrm{pH} 8.0$, $150 \mathrm{mM}$ sodium chloride, $5 \mathrm{mM}$ ethylenediaminetetraacetic acid (EDTA), 1\% NP-40, 0.02\% $\mathrm{NaN}_{3}, 50 \mathrm{mM} \mathrm{NaF}$ and protease inhibitors (1 $\mathrm{mM}$ phenylmethanesulfonyl fluoride (PMSF), $1 \mu \mathrm{g} / \mathrm{ml}$ aprotinin). The extracts were obtained by centrifugation at $12,000 \mathrm{x} \mathrm{g}$ and $4^{\circ} \mathrm{C}$ for $10 \mathrm{~min}$. The concentration of protein was measured using the BCA protein assay kit (Thermo Scientific). Equal amounts of proteins were separated on $12 \%$ sodium dodecyl sulfate-polyacrylamide gel electrophoresis (SDS-PAGE) and transferred onto polyvinyldifluoride (PVDF) membranes. The primary antibodies (Abcam, San Francisco, CA, USA) against GAPDH (ab110305), Livin (ab97516), VEGF (ab46154), VEGFR-2 (ab39256), MMP-2 (ab86607) and MMP9 (ab119906) were diluted according to the instructions of antibodies and incubated overnight at $4^{\circ} \mathrm{C}$. Then, the HRP-conjugated secondary antibody (ab6721) was added at a dilution ratio of 1:1,000, and incubated at room temperature for $2 \mathrm{~h}$. The membranes were immunoprobed with corresponding antibody, and visualized using an enhanced chemiluminescence reagent (Thermo Scientific).

MTT assay. The exponentially growing A549 cells were seeded in 96-well plates at a density of $8 \times 10^{3}$ cells/well in media and left overnight to allow cell adherence. Following incubation for 1,2 or 3 days at $37^{\circ} \mathrm{C}$, cell viability was measured by adding $20 \mu \mathrm{l}$ of $5 \mathrm{mg} / \mathrm{ml} 3$-(4,5-dimethylthiazol-2-yl)-2,5-dipheny ltetrazolium bromide (MTT) to each well, and incubated at $37^{\circ} \mathrm{C}$ for a further $4 \mathrm{~h}$, after which the media were substituted with $200 \mu \mathrm{l}$ DMSO for formazan crystal dissolution. The absorbance was measured using a micro-plate reader (Thermo Scientific) at $570 \mathrm{~nm}$. The data are presented as the percentage of surviving transfected cells vs. control cells (viability of control cells was considered to be $100 \%$ ).

Colony-formation assay. Lung cancer cells treated with or without transfection were plated on 6-well plates at a density of 1,000 cells/well. The culture medium was refreshed after 
$24 \mathrm{~h}$ of incubation. After 7 days of culture, the colonies were stained with $0.5 \%$ of methylene blue, fixed with $4 \%$ paraformaldehyde for $2 \mathrm{~h}$, and counted under a microscope (Olympus Corp., Tokyo, Japan).

Transwell invasion assay. Cell invasive ability was assessed using a 24-well $8.0 \mu \mathrm{m}$ Transwell chamber (Corning Inc., Corning, NY, USA) coated with Matrigel $(1 \mathrm{mg} / \mathrm{ml}$, BD Biosciences, Franklin Lakes, NJ, USA). After being starved in serum-free medium for $24 \mathrm{~h}, 1 \times 10^{5}$ cells in $200 \mu \mathrm{l}$ serumfree medium were harvested and seeded in the top chamber, and $600 \mu 1$ 10\% FBS-RPMI-1640 medium was added to the lower chamber. Twenty-four hours later, the non-migrated cells were gently removed with cotton swabs and the migrated cells on the bottom surface of the membrane were fixed with $4 \%$ paraformaldehyde for $30 \mathrm{~min}$. The cells were then stained with hematoxylin and eosin (H\&E), quantified by manual counting and images were captured under a light microscope. Rates of cellular invasion through Matrigel were normalized by that of control cells. Five randomly chosen fields were analyzed for each group.

Gelatin zymography assay of MMP-2 (Gelatinase A) and MMP-9 (Gelatinase B). Proteins in the culture supernatant collected in equal amounts of the cell medium were then separated in $10 \%$ SDS-PAGE gel $(0.1 \% \mathrm{w} / \mathrm{v}$ of gelatin) under non-reducing conditions at $4^{\circ} \mathrm{C}$. After electrophoresis, the gel was washed in $2.5 \% \mathrm{v} / \mathrm{v}$ of Triton $\mathrm{X}-100$ for $30 \mathrm{~min}$ at room temperature for renaturing with gentle agitation. The gel was subsequently incubated in assay buffer $(50 \mathrm{mmol} / \mathrm{l}$ Tris $\mathrm{HCl}$, $5 \mathrm{mmol} / 1 \mathrm{CaCl}_{2}, 0.02 \%$ Brij-35, $\mathrm{pH} 7.6$ ) for $42 \mathrm{~h}$ with gentle shaking. The gel was stained with solution $(0.05 \%$ Coomassie blue, $30 \%$ methanol, $10 \%$ acetic acid) and sequentially destained. Gelatinolytic bands were detected as transparent zones against the blue background and densitometric analysis of the bands was performed using ImagePro Plus software (Media Cybernetics, Silver Spring, MD, USA).

Enzyme-linked immunosorbent assay (ELISA). When showing logarithmic growth, the cells were collected and plated into 6 -well culture plates at a density of $2 \times 10^{5}$ cells/well. Cell culture supernatants in serum-free medium were homogenized and harvested $72 \mathrm{~h}$ later and centrifuged at $1000 \mathrm{x} \mathrm{g}$ for $20 \mathrm{~min}$. The levels of VEGF were subsequently determined using commercially available ELISA kits, product no. SEA143Hu (Uscn Life Science, Wuhan, China), according to the manufacturer's instructions.

In vivo tumor xenograft study. The protocol for the animal experiment was approved from the Institutional Animal Ethics Committee, Experimental Animal Center of Fujian Medical University, China. All surgery was performed under anesthesia and efforts were taken to minimize animal suffering. Seventy-five immunodeficient male BALB/C nude mice, 4-5 weeks old (SLAC Laboratory Animal Co. Ltd., Shanghai, China) were randomly divided into three groups with 25 per group: 16 for dynamic monitoring and the remaining 9 for the survival study. The three groups of A549 cells were resuspended in $0.1 \mathrm{ml} \mathrm{PBS}$ and intravenously injected into the lateral tail vein at a density of $2.5 \times 10^{6}$ cells/mouse in the corresponding animal groups. At 5, 6, 7 and 9 weeks after cell inoculation, 4 of 25 mice were randomly chosen, sacrificed by deep anesthesia and visualization of cancer-cell expressing eGFP dynamics during lung metastasis in live mice was performed using the imaging system IVIS lumina II (Caliper Life Sciences, Boston, MA, USA). Mouse body weight was measured every two to three days throughout their lifespan. After macroscopic observation, the harvested tissues from the three groups of nude mice were weighed, processed and conserved for the follow-up experiments. Tissues were stained with $H \& E$ to further evaluate lung metastasis generation dynamically and precisely. The mice in the survival study were euthanized when they became severely cachectic and the day of euthanasia was considered the end point of follow-up observation.

Immunohistochemical analysis. Tissues from the sacrificed mice were fixed in formaldehyde overnight, and then dehydrated and coated with wax. Tissues sections $(3-\mu \mathrm{m})$ were prepared and then subjected to de-paraffining and antigen retrieval. Tissues were blocked with endogenous peroxidase for $10 \mathrm{~min}$ followed by protein block for $10 \mathrm{~min}$ at room temperature and were incubated with primary antibody (Abcam) (1/200 in antibody diluent) for $2 \mathrm{~h}$ at $20^{\circ} \mathrm{C}$, then ready-made $\mathrm{HRP}$-conjugated antibody (Abcam) for $30 \mathrm{~min}$ at $20^{\circ} \mathrm{C}$. The sections were counterstained with diaminobenzidine (DAB) chromogen substrate and hematoxylin, and the presence of a brown precipitate indicating immunoreactivity was examined under a microscope. Assuming that the intensity of immunoreactivity was correlated with the level of gene expression, semi-quantitative analysis of tissue samples was conducted using ImagePro Plus software. The images were captured by microscopy.

Statistical analysis. SPSS 19.0 was used for data analysis. The data are expressed as means \pm SD from independent experiments. Statistical significance was determined using the Student's two-tailed t-test in two groups and one way ANOVA in multiple groups. Kaplan-Meier survival curves and P-values of group comparisons were conducted for survival analysis. A P-value of $<0.05$ was considered statistically significant.

\section{Results}

A549 cells were stably transfected with Livin specific shRNA expression vector. The rate of effective transfection in the three groups of cells was monitored by fluorescence microscopy. Over $95 \%$ of cells transfected with lentiviral vectors showed green fluorescence in the KD and NC groups, however, no GFP expression was observed in the wild-type A549 cells, which indicated successful transfection (Fig. 1A). To determine the effect of Livin-shRNA in A549-RNAi cells, the mRNA levels of Livin were analyzed by real-time PCR assay. The GAPDHnormalized Livin mRNA expression is shown in Fig. 1B. As, expected, Livin mRNA expression in A549-RNAi cells was the lowest, clearly showing the constitutive downregulation of Livin. There were significant differences between A549-RNAi cells and both NC-LV and non-transfected A549 cells. The efficient silencing of Livin was confirmed by western blotting. Densitometric measurements revealed that the expression of 


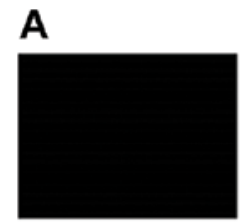

Blank control

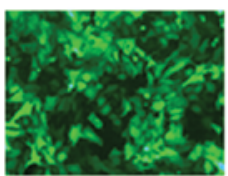

NC-LV

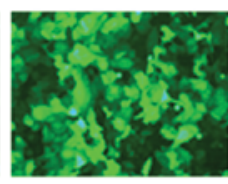

Livin-LV
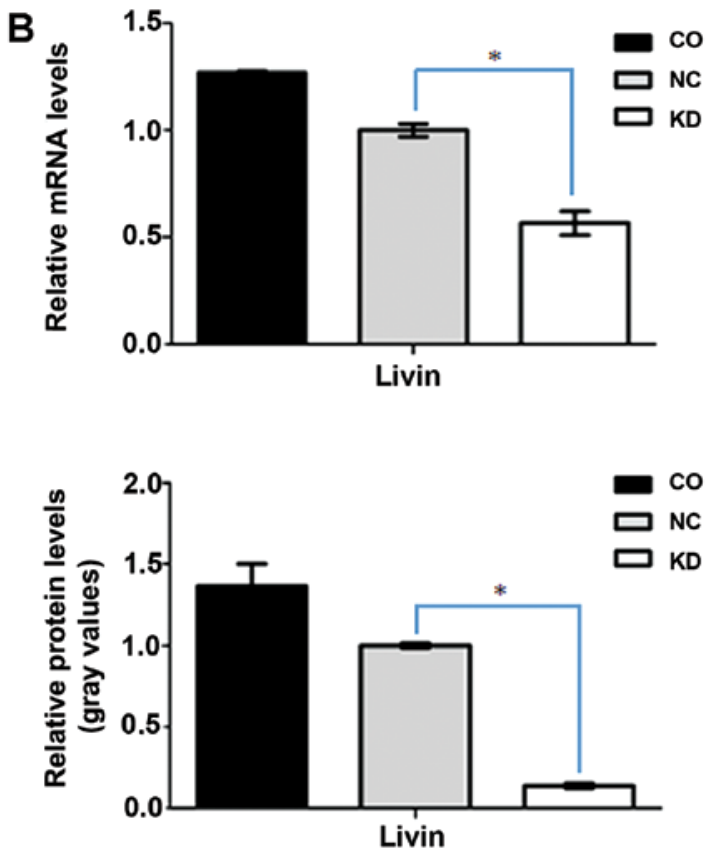

Figure 1. Effect of Livin-shRNA on inhibition of lung cancer A549 cells. (A) Fluorescent microscopy image. Intensity of green fluoescence indicated the transfection efficiency. (B) Livin mRNA expression was estimated by real-time PCR. GAPDH was detected as the control. (C) The protein level of Livin was detected by western blots. GAPDH expression was detected as loading control. Densitometric analysis of protein levels of Livin. Data are the mean \pm SD of three independent experiments relative to GAPDH. Shown are representative images. The statistical significance is marked with * $(\mathrm{P}<0.05)$.

A
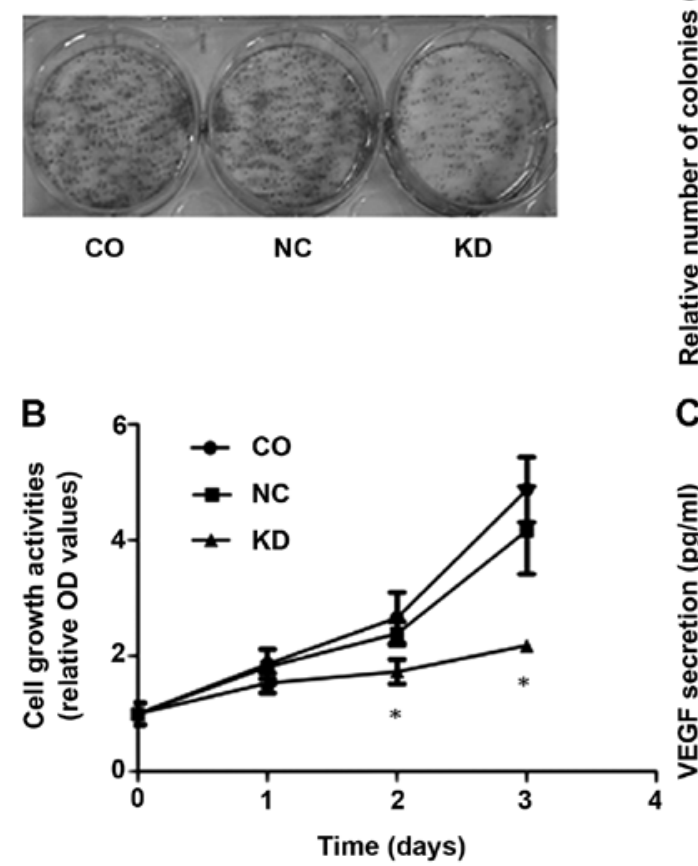

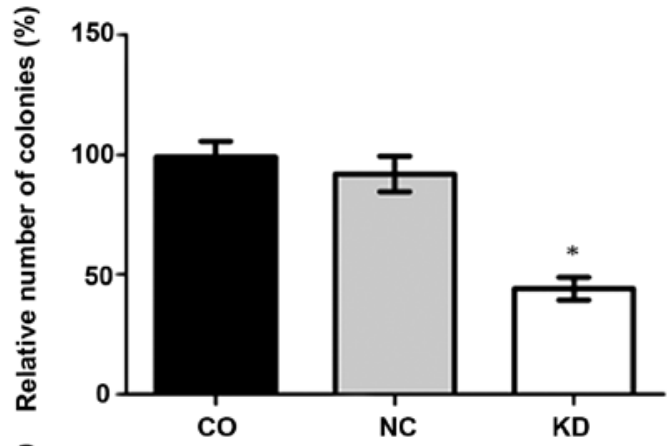

C

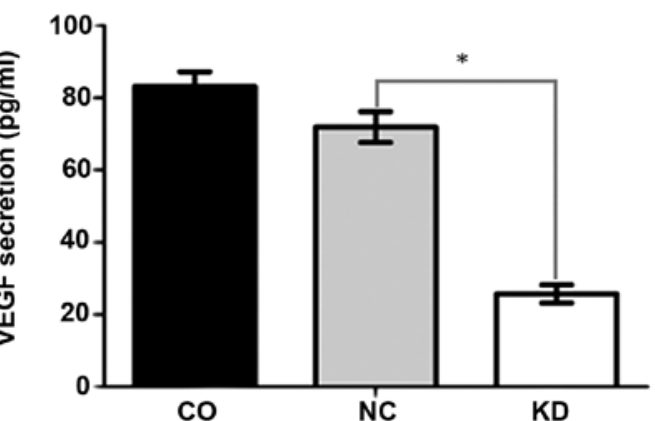

Figure 2. Effect of Livin knock-down on lung cancer cell viability in vitro. (A) Quantitative analysis of plate colony formation of A549 cells. (B) The cell viability was analyzed by MTT with cell growth at 24,48 or $72 \mathrm{~h}$. (C) ELISA analysis of extracelluar VEGF release in supernatant. All data are expressed as mean $\pm \mathrm{SD}$ of three independent experiments. The statistical significance is marked with ${ }^{*}(\mathrm{P}<0.05)$.

Livin protein decreased sharply in A549-RNAi cells, and was reduced by $86 \%$ compared with wild-type A549 cells (Fig. 1C).

Effect of Livin small hairpin RNA on cell proliferation and cell growth. The effect of Livin downregulation on transfected cell proliferation was determined by colony formation assay.
As shown in Fig. 2A, a significantly lower colony number was observed in A549-RNAi cells than in NC-LV or blank control cells $(\mathrm{P}<0.001)$. The colony number in A549-RNAi cells was reduced by $52 \%$. To gain further insight into the effect of Livin shRNA on A549 cell growth, the metabolic activity of these cells was quantified by MTT assay. Additional comparisons 

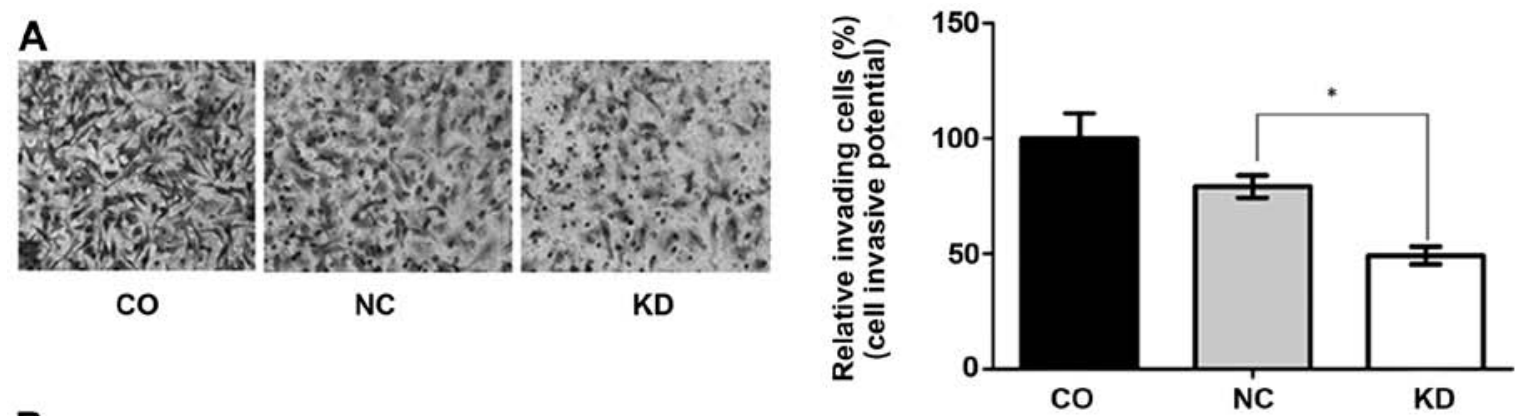

B
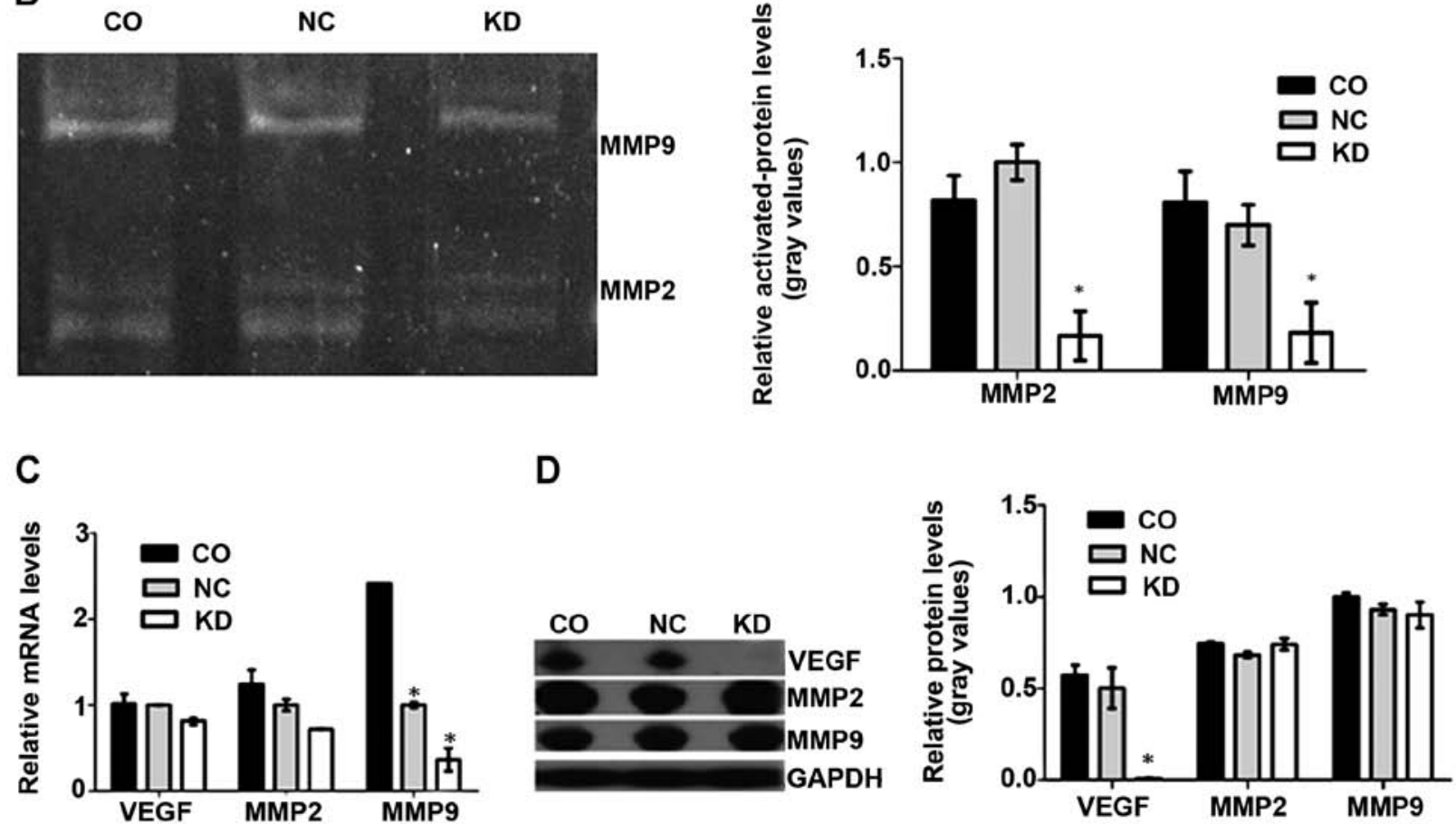

Figure 3. Impact on VEGF, and MMPs based on silencing of Livin in vitro. (A) Effect of Livin downregulation on cells invasion. Invasive cells passed through the membrane in Tranwell assay. (B) MMP-2/-9 activities were detected using gelatin zymography technique. (C) Transcription of VEGF and MMP-2/-9 were determined by QPCR. (D) VEGF and MMP-2/-9 were examined by western blots and densitometry analysis compared with GAPDH. Data are the mean \pm SD of three independent experiments relative to GAPDH. The statistical significance was marked with ${ }^{*}(\mathrm{P}<0.05)$. Shown are representative images.

showed that growth of the stably expressing Livin shRNA cells was slower. Compared with the vector control or blank control cells, significant differences were noted in growth rates on the second day $(\mathrm{P}<0.005)$, which were amplified on the third day $(\mathrm{P}<0.001)$. The growth rates of the vector control cells were not significantly different from the blank control A549 cells (Fig. 2B).

In addition, to detect whether Livin knock-down affected extracellular VEGF, ELISA was performed to quantify the amount of VEGFA secreted into the culture media. The inhibitory effect on VEGFA protein levels was demonstrated by a significant decrease in VEGFA concentration in the media containing A549-RNAi cells $(25.7 \pm 2.5 \mathrm{pg} / \mathrm{ml})$ compared with the vector control group $(71.9 \pm 4.3 \mathrm{pg} / \mathrm{ml})$ and the control group $(83.1 \pm 4.1 \mathrm{pg} / \mathrm{ml})(\mathrm{P}<0.001)$ (Fig. $2 \mathrm{C})$. Real-time PCR and western blot analysis were carried out to investigate intracellular VEGF expression. The data, summarized in Fig. 3C and $\mathrm{D}$, indicated a marked decrease in VEGF protein expression in A549-RNAi cells. The data described above suggest that knock-down of Livin suppressed VEGFA secretion, as well as intracellular VEGF expression. In contrast, no signifi- cant differences $(\mathrm{P}>0.05)$ in the expression level between the vector control and blank control were observed.

Knock-down of Livin suppresses cell invasion in vitro through the MMPs signaling pathway. To gain knowledge on the effect of Livin knock-down on A549 cell invasion, we evaluated the invasive ability of cells using a Transwell assay. The results indicated that the number of A549-RNAi cells which passed through the Matrigel-coated membranes was significantly less than that of the negative control or blank control A549 cells $(\mathrm{P}<0.001)$ (Fig. 3A). We performed gelatin zymography to determine whether Livin knock-down inhibited cell invasion via downregulation of activated forms of MMP-2/-9. The marked decrease in invasive ability of the A549-RNAi cells was further confirmed, and statistically significant differences in MMP-2 and MMP-9 activities, which declined by $>50 \%$, were observed between the two groups of cells (Livin-LV, vector-LV) (Fig. 3B). No differences in activated MMP-2 and MMP-9 between the negative control and blank control group were observed. To detect total MMP expression, real-time PCR and western blot analysis were conducted. Fig. 3C and D 
A

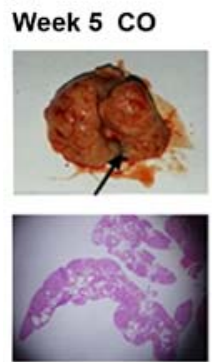

Week 9 co
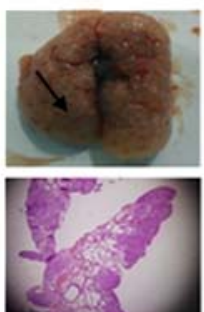
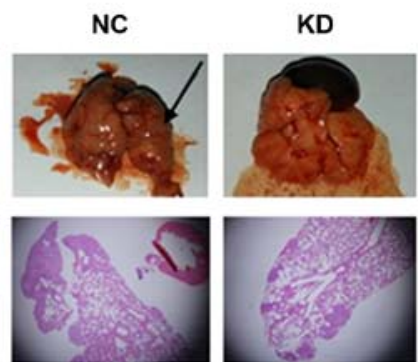

NC

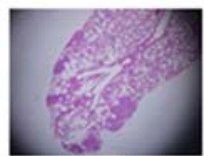

KD
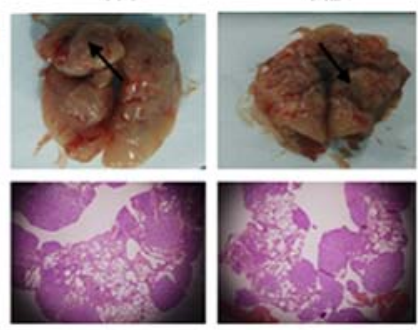

B

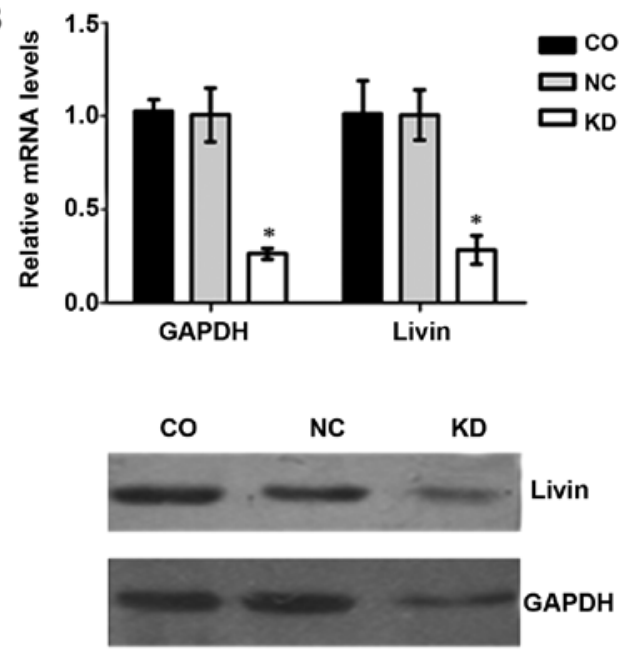

C

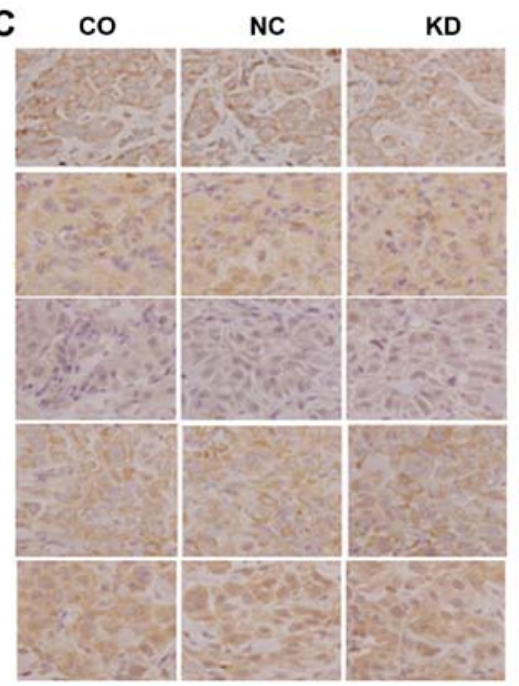

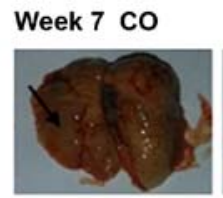
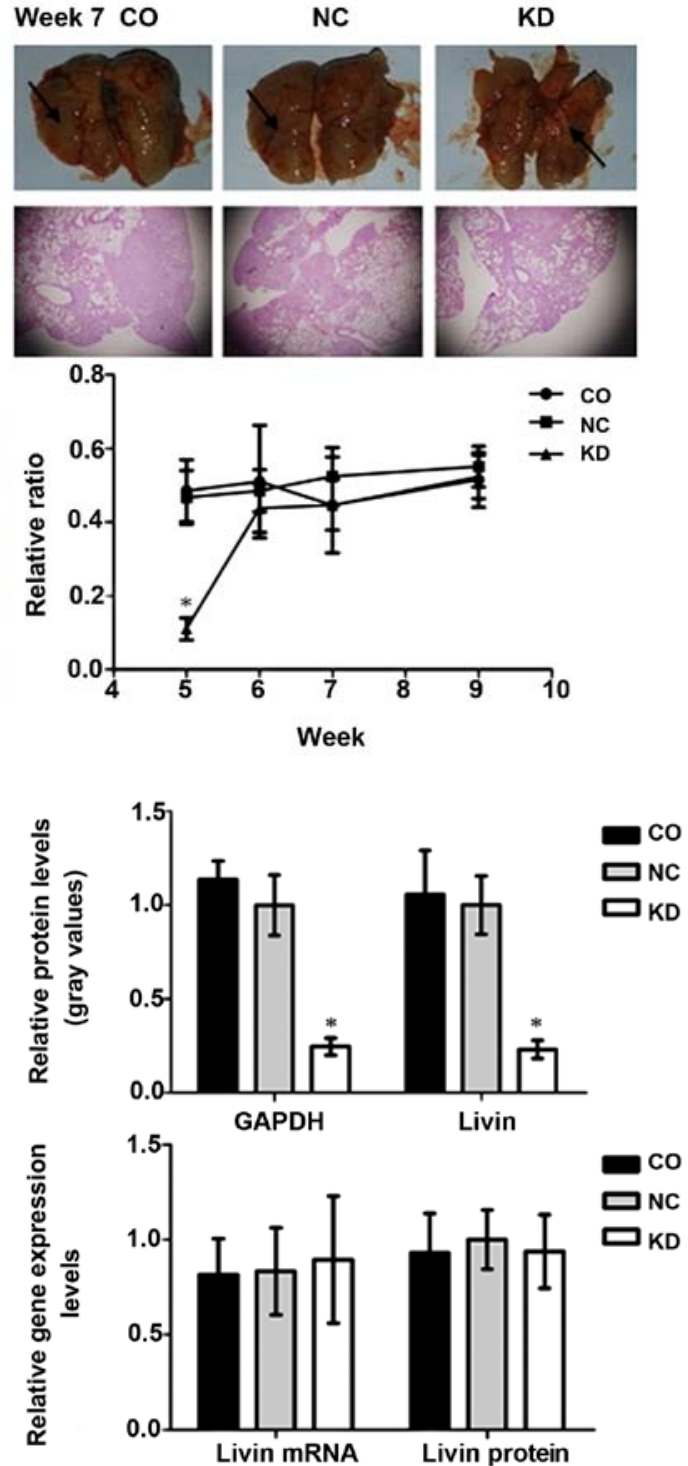

Livin
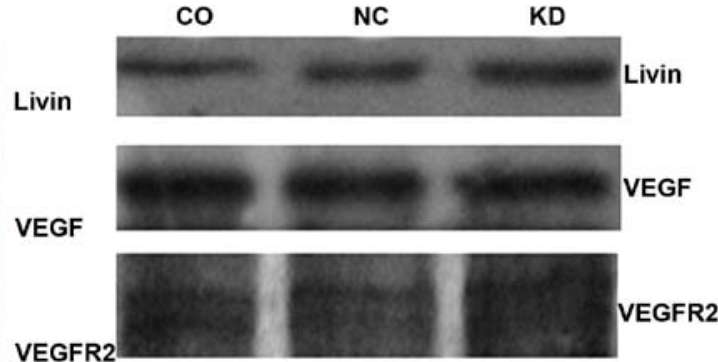

VEGFR2

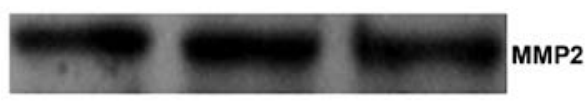

MMP2

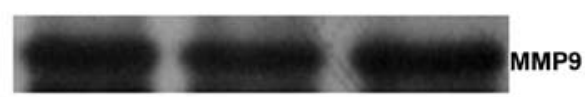

MMP9

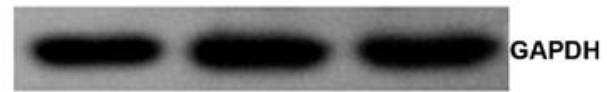

Figure 4. Effect of Livin-shRNA on inhibition of tumor nodules formation in vivo. (A) Gross view and microscopic pathology of lungs with H\&E staining (original magnification $\mathrm{x} 40$ ). Further analysis of the relative ratio of tumor areas to the whole lung. Black arrow indicates representative tumor nodules. (B) Gene expression after five weeks of cell inoculation. Cell extracts were examined by QPCR and western blots, densitometry analysis is presented without normalizing. Further analysis of Livin gene expression is exhibited as GAPDH-normalized densitometry analysis. (C) The expression and protein localization of genes which were associated with the Livin signaling pathway (original magnification x100), including gene VEGFR2/KDR, known as a direct downstream target of VEGF. All data are the mean $\pm \mathrm{SD}$ of three independent experiments. Shown are representative images. ${ }^{*} \mathrm{P}<0.05$ when compared with control group by ANOVA. 


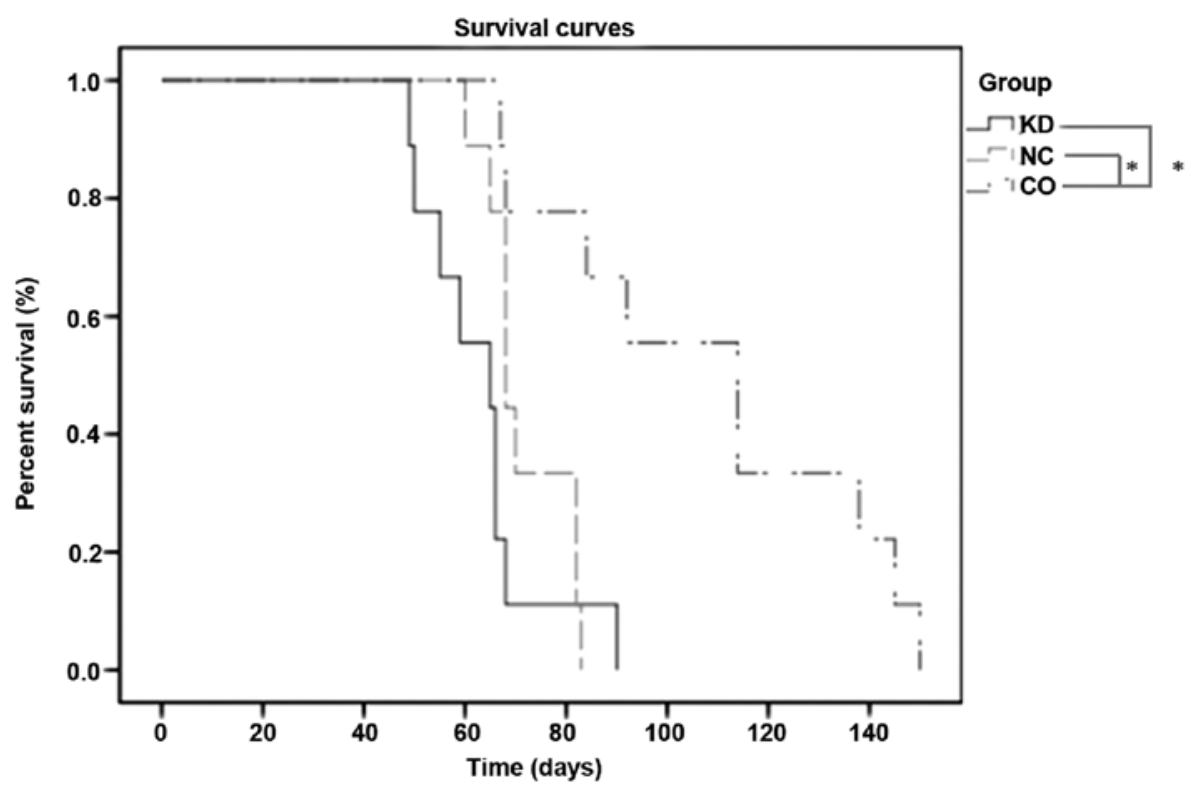

Figure 5. Kaplan-Meier curves representing overall survival of tumor-bearing mice in different groups. Statistical analysis was conducted using the log-rank test $\left(\mathrm{n}=9,{ }^{*} \mathrm{P}<0.05\right)$.

show significant differences in total mRNA level among the three groups, while no significant differences in total MMP protein level was noted.

Silencing of Livin preventes the formation of tumor nodules resulting from impaired metastasis and neoangiogenesis in vivo. To explore Livin gene function in the development of lung cancer in vivo, the mice with successfully constructed lung cancer were sacrificed. Lung metastasis occurred in $100 \%$ of the mice injected with tumor cells. Five weeks after cell inoculation, scattered tumor nodules which showed a soft texture and a greyish-white color in the NC and CO groups were occasionally seen by the naked eye in comparison with the KD group which showed no visible tumor nodules. The already formed tumor nodules were of unequal size and unevenly distributed in the lung under the microscope. The pathological result showed that the relative ratio of the areas with pulmonary nodules to the total lung tissue area was the least in the KD group. In the other two groups, the ratio was not significantly different $(\mathrm{P}>0.05)$. At 6, 7 and 9 weeks after cell inoculation, gross view and microscopic pathology showed no significant differences between the three groups. Based on tumor formation in the lungs at the different time points, week seven was considered as the stationary phase in which the size of tumors in the experimental group changed slightly, in contrast to the period from week five to week six (Fig. 4A).

To determine the transcription and translation of Livin and associated genes in vivo, we used real-time PCR and western blot analysis. During genomic and proteomic detection of either $G A P D H$ or Livin, to avoid cross-reaction between cancer nodules derived from human lung cancer cells and normal lung tissues of mice, we chose human-specific primers and antibodies. Five weeks after cell inoculation, the human specific GAPDH and Livin mRNA, as well as their protein content in the mixed tissue in the KD group showed significant differences compared with the $\mathrm{NC}$ and $\mathrm{CO}$ group $(\mathrm{P}<0.011)$.
These differences were consistent with the relative ratio of the areas with tumor nodules which could represent the volume of tumor nodules formed in the lungs. Analysis of the human specific GAPDH-normalized Livin mRNA and protein levels in the KD group showed no significant differences compared with those in the NC and CO group (Fig. 4B). Taking the distinct areas of formed pulmonary nodules into consideration, we further analyzed the models to confirm the differences between the three groups at 7 weeks after cell inoculation, at which time the pulmonary nodules were assumed to be stably formed. As expected, no differences were observed $(\mathrm{P}>0.05)$ (Fig. 4C).

To further evaluate the anti-metastatic activity of Livin, we conducted a survival study. Unexpectedly, mice inoculated with wild-type A549 cells had a significantly longer mean survival time (114 days) compared with 65 days for mice inoculated with A549-RNAi cells and 68 days for mice inoculated with NC-LV cells $(\mathrm{P}<0.001)$ (Fig. 5). In vivo imaging after intravenous injection showed no fluorescence in the lungs, although microscopic pathology confirmed the presence of lung metastasis. There were only false positive areas of increased uptake (Fig. 6). The correlation of the lung weight, the mouse body weight and the relative ratio of the areas with pulmonary nodules was analyzed to figure out whether the weight of lungs could reflect the volume of tumor nodules formed in the lungs, as seen in Fig. 7, there was a positive correlation between the lung weight and the relative ratio of the areas with pulmonary nodules $\left(\mathrm{R}^{2}=0.789\right)$, however, no correlation exists between the lung weight and the mouse body weight (nine mice were randomly selected).

\section{Discussion}

Livin, a novel IAP family protein, plays crucial roles in the regulation of cell proliferation, cell cycle and apoptotic death $(20,21,23)$. Increasing number of studies reveal that 

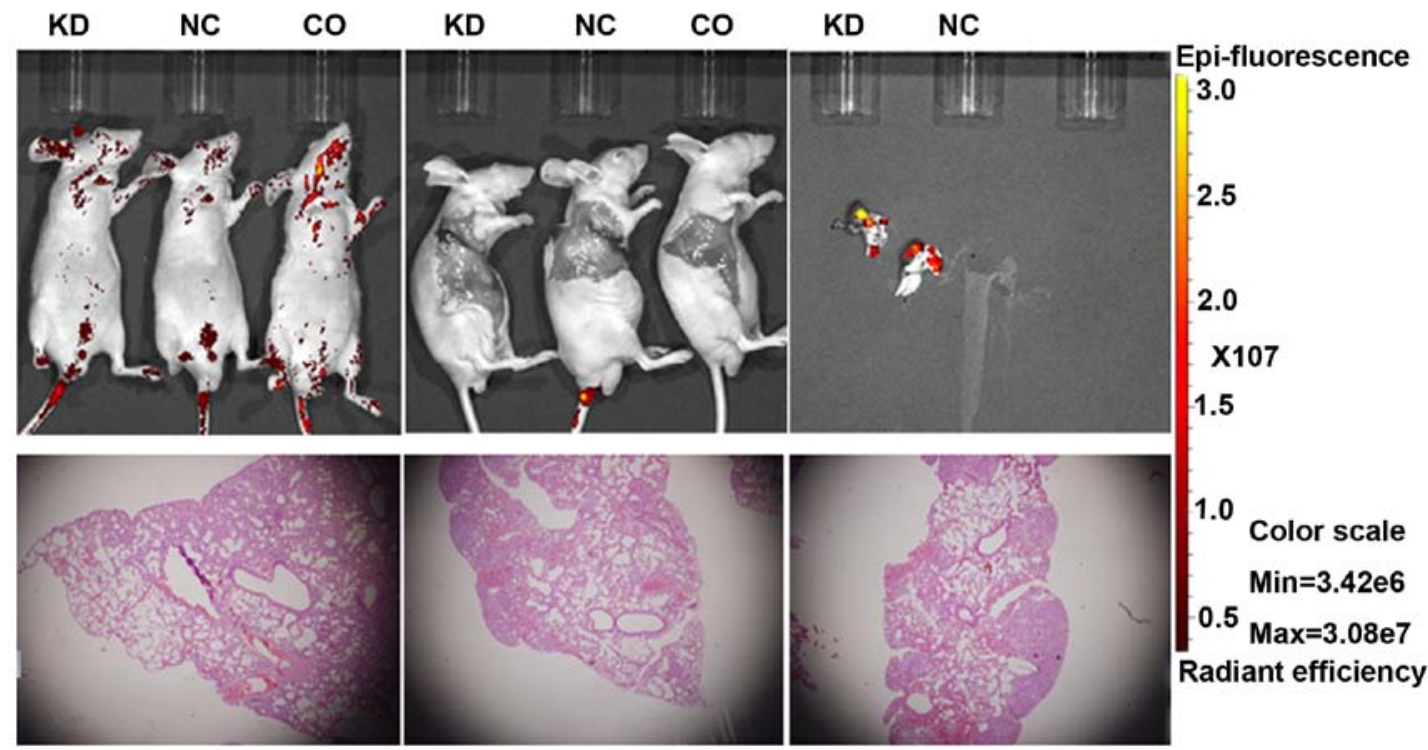

Figure 6. In vivo fluorescence image of the IVIS Lumina II system and microscopic pathology with H\&E staining (original magnification $\mathrm{x} 40)$ of the lungs. There were only false positive areas of increased uptake. IVIS Lumina II parameter: f/stop 2 , exposure time $1 \mathrm{sec}$, binning $4 \mathrm{x} 4$, filters $\lambda \mathrm{ex}=640 \mathrm{~nm} / \lambda \mathrm{em}=720 \mathrm{~nm}$. Shown are representative images.
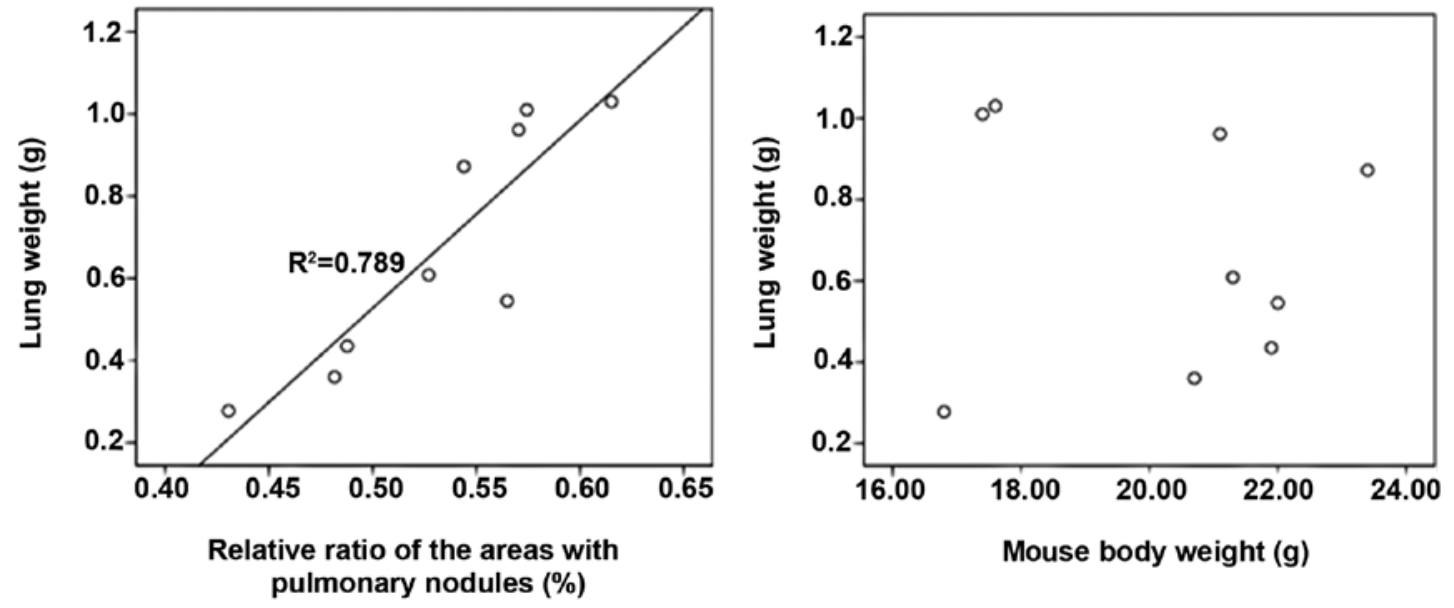

Figure 7. The scatterplot revealed a positive association between the lung weight and the relative ratio of the areas with pulmonary nodules, however, no association between the lung weight and the mouse body weight $(\mathrm{n}=9)$.

Livin can inhibit apoptosis induced by a variety of stimulus, while it is specifically cleaved by caspases on a strong apoptotic stimulus to produce a truncated protein which inversely harbors the death-promoting activity, indicating a dual role of Livin in cell biology $(10,24-26)$. The subcellular localization of Livin can be an alternative mechanism that regulates the balance between the anti- and pro-apoptotic activity of Livin (27). However, Livin is involved in networks of closely related molecules and factors, and regulates the cell function by numerous cross-communication methods, which has made it a promising target for the development of potential gene therapy. Thus, we developed a novel experimental animal model to examine the effect of Livin in lung cancer.

The safety and efficiency of the lentiviral vector transduction system, which did not alter the biological characteristics of the cells or survival time of the animal models, caused substantial expression of genes over 20 weeks (28-30). In the current study, using the Livin specific shRNA expression vector for gene knock-down, we successfully achieved stable suppression of Livin expression in A549 cells. Downregulation of Livin expression not only led to slower cell proliferation and growth rate, but also regulated downstream gene expression resulting in inhibition of cell invasion. In this study, it was found out that genetic downregulation of Livin inhibited cell proliferation and growth by causing a marked decrease in VEGF (almost to 0\% at the translation level). The mRNA expression which was not in line with the protein expression suggested that transcription accounted for only a minor fraction of gene expression. VEGF, also known as VEGFA, has a number of functions in tumor progression. According to the origin of VEGF, it is generally classified as autocrine VEGF which participated in cell survival, and was identified as a contributor to the size of the cancer stem cell pool (31) and paracrine VEGF which conveyed critical signals 
for cell biological behavior including proliferation and permeability responses (32). In the present study consistent findings were recorded by real-time PCR and western blotting, Livin knock-down interfered with both forms of VEGF causing a sharp reduction in VEGF secretion by A549 cells in vitro. The MMPs, which are key nodal proteases and control the protease web, consist of a large family with nearly 30 members (33). MMP2 and MMP9, known as gelatinases, are considered to be involved in cell invasion. We showed that total expression levels of MMPs were indistinguishable on the basis of Livin silencing, in sharp contrast to the change in the activated forms of MMPs. Although, the three main levels including transcription, proenzyme activation and inhibition control MMP proteolytic activity in the cells (34), the invasion ability of lung cancer cells is attributed to the transformation of MMPs from pro-MMPs to activated forms other than alteration in the total MMP expression. Thus, specific cells have their own distinguishable mechanism in the mediation of genome and proteome.

BALB-nude mice, which congenitally lack immunological $\mathrm{T}$ cells have a leading role in anticancer immunity, but are characterized by abundant B cells and inherited immune components including cytokines and natural killer cells. In the present study, we used BALB-nude mice as in vivo models for a better evaluation of the interactions between xenotransplanted tumors and host defense due to their immunodeficiency background. There are many approaches for the analysis of metastases: subcutaneous, intraperitoneal, orthotopic, intracardiac and intravenous injection. The intravenous approach which was used in our study was customized for the lung metastasis assay based on the rationale that the pulmonary vascular bed acted as the first station for tumor cells injected via the mouse lateral tail vein. Lung cancer cells in the blood circulation were blocked in the pulmonary capillary bed, and penetrated the blood vessel wall mimicking the metastasis process after the intravasation step. Subsequently, when the cancer cells arrested in the lung, the tumorigenesis process began (2). In this study, the lentivirus vector transfected cells were used instead of the separate application of vectors and tumor cells, because the extraneous vectors in the circulating blood might motivate the animal defense to reversely neutralize the imminent transfection (35).

The animals which were euthanized at different time points, enabled a dynamic follow-up of the way Livin functioned in vivo. Five weeks after tumor implantation, a significant decrease in tumor burden in the experimental group strongly indicated anti-metastasis and tumorigenesis inhibition. This was ascribed to several reasons e.g., reduced MMPs expression in the treatment group meant less metastatic ability, and resulted in fewer cells settling in the lung (36). Following this, cells proliferated, but the LV-shRNA transfected cells impeded tumor expansion because of the impairment of tumor neoangiogenesis resulting from VEGF inhibition. Further analysis of human specific GAPDH-normalized Livin expression and the correlated genes in Livin modulated signal-transduction pathways indicated reduced transfection efficacy, i.e., transfected tumor cells which accounted for over $95 \%$ of the total cells injected into the mice were eliminated due to decreased invasive ability, and the minority of untransfected cells, which were arrested in the lung, expanded and led to oncogenesis. Moreover, the gradual development of tumors from the outer to the inner areas of the lungs seen on microscopic pathology (Fig. 4A) was regarded as evidence that tumor cells were arrested in the microvascular bed. In the three groups, the lung cancer stage was not uniform, the stage of the neoplastic process affected by Livin-targeted therapy in the experimental group tended to be earlier. Overall, an important conclusion drawn from our studies was that Livin was characterized by stage-independent expression in lung adenocarcinoma cells (37) and the growth of lung cancer followed an S-shaped curve (Fig. 4A). With regard to vectors encoding eGFP, the fluorescence microscopy for their real-time imaging was feasible (38-40). In our work, we used lentiviral vectors encoding eGFP as a dynamic fluorescent tracer but obtained a negative outcome, although we further opened skin-flap window and cut out the lungs for fluorescent imaging. One probable explanation was that the low aggregation of tumor nodules accounted for the negative results and the IVIS system was not fit for fluorescence imaging of tumors inside the mouse body $(41,42)$, but rather the bioluminescent imaging (43). In the subcutaneous models, the reduction in tumor weight and tumor volume followed Livin gene silencing $(9,21)$. In the intravenous models, the xenografts grew larger as the tumor progressed, and the lung weight was correlated with the relative ratio of the areas with tumor nodules which represented the volume of the tumor in situ, although the interaction between lung cancer and the host might influence the lung weight. Taken together, we demonstrated that the experimental models were reliable and reproducible in our work. In addition, we postulate that prolonged survival should have been elicited in the experimental group because our previous study demonstrated that the local injection of lentivirus-delivered Livin shRNA effectively suppressed lung carcinoma development with minor adverse reactions. It is essential to elucidate whether eGFP, in addition to other components of the heterogeneous tumor cell lysates, are toxic to cells and amplify the arousal responses to antigen in the anti-neoplastic inflammatory process during the intravenous injection approach $(44,45)$ and vectors encoding Luciferase may be an alternative.

In conclusion, our findings indicate that knock-down of Livin inhibits cell growth and invasion through blockade of the VEGF and MMPs pathways in lung cancer cells in vitro, and inhibits tumorigenesis and metastasis of lung cancer in vivo, suggesting that Livin may be an appropriate anticancer target for the treatment of lung cancer. This is the first demonstration that tumorigenesis and metastasis of lung cancer can be investigated in a reliable and reproducible experimental animal model in a time-dependent manner.

\section{Acknowledgements}

This study was supported by a grant (no. 2011J01130) from the Natural Science Foundation of Fujian Province, China and a grant (no. WKJ-FJ-17) from the scientific research fund of the National Board of health and family planning, China. The authors would like to compliment the staff of the Pathology Department in Fujian Provincial Hospital. The authors would also like to thank Cardiovascular Key Laboratory of Fujian Province, Experimental Animal Center of Fujian Medical University and the CDC of Fujian Province, China, 
for providing us with necessary conditions and facilities to complete this project.

\section{References}

1. Coleman MP, Forman D, Bryant H, Butler J, Rachet B, Maringe C, Nur U, Tracey E, Coory M, Hatcher J, et al; ICBP Module 1 Working Group: Cancer survival in Australia, Canada, Denmark, Norway, Sweden, and the UK, 1995-2007 (the International Cancer Benchmarking Partnership): An analysis of populationbased cancer registry data. Lancet 377: 127-138, 2011.

2. Chambers AF, Groom AC and MacDonald IC: Dissemination and growth of cancer cells in metastatic sites. Nat Rev Cancer 2: 563-572, 2002.

3. Bissell MJ and Radisky D: Putting tumours in context. Nat Rev Cancer 1: 46-54, 2001.

4. Yan B, Kong M, Chen S and Chen YH: VEGF stimulation enhances Livin protein synthesis through mTOR signaling. J Cell Biochem 111: 1114-1124, 2010.

5. Funahashi Y, Shawber CJ, Sharma A, Kanamaru E, Choi YK and Kitajewski J: Notch modulates VEGF action in endothelial cells by inducing Matrix Metalloprotease activity. Vasc Cell 3: 2, 2011

6. Shan B, Li W, Yang SY and Li ZR: Estrogen up-regulates MMP2/9 expression in endometrial epithelial cell via VEGFERK1/2 pathway. Asian Pac J Trop Med 6: 826-830, 2013.

7. Enciso JM, Gratzinger D, Camenisch TD, Canosa S, Pinter E and Madri JA: Elevated glucose inhibits VEGF-A-mediated endocardial cushion formation: Modulation by PECAM-1 and MMP-2. J Cell Biol 160: 605-615, 2003.

8. Ebrahem Q, Chaurasia SS, Vasanji A, Qi JH, Klenotic PA, Cutler A, Asosingh K, Erzurum S and Anand-Apte B: Cross-talk between vascular endothelial growth factor and matrix metalloproteinases in the induction of neovascularization in vivo. Am J Pathol 176: 496-503, 2010.

9. Ou JM, Ye B, Qiu MK, Dai YX, Dong Q, Shen J, Dong P, Wang XF, Liu YB, Quan ZW, et al: Knockdown of Livin inhibits growth and invasion of gastric cancer cells through blockade of the MAPK pathway in vitro and in vivo. Int J Oncol 44: 276-284, 2014.

10. Lazar I, Perlman R, Lotem M, Peretz T, Ben-Yehuda D and Kadouri L: The clinical effect of the inhibitor of apopotosis protein livin in melanoma. Oncology 82: 197-204, 2012.

11. Haferkamp A, Bedke J, Vetter C, Pritsch M, Wagener N, Buse S, Crnkovic-Mertens I, Hoppe-Seyler K, Macher-Goeppinger S, Hoppe-Seyler F, et al: High nuclear Livin expression is a favourable prognostic indicator in renal cell carcinoma. BJU Int 102: 1700-1706, 2008.

12. Sun JG, Liao RX, Chen ZT, Wang ZX, Zhang Q, Hu YD and Wang DL: Gene transfection of Livin isoforms into A549 cell line and its effect on cell growth and sensitivity to chemotherapy and radiotherapy. Zhonghua Jie $\mathrm{He} \mathrm{He} \mathrm{Hu} \mathrm{Xi} \mathrm{Za} \mathrm{Zhi} \mathrm{28:} \mathrm{836-840,}$ 2005 (In Chinese).

13. Lee DH, Yoon TM, Kim SA, Park YL, Lee KH, Lim SC, Lee JK and Joo YE: Relationship between expression of Livin and the biological behavior of human oral squamous cell carcinoma. Oncol Rep 32: 2453-2460, 2014.

14. Yoon TM, Kim SA, Lee DH, Lee JK, Park YL, Lee KH, Chung IJ, Joo YE and Lim SC: Expression of Livin and the inhibition of tumor progression by Livin silencing in laryngohypopharyngeal cancer. In Vivo 28: 751-759, 2014.

15. Li F, Yin X, Luo X, Li HY, Su X, Wang XY, Chen L, Zheng K and Ren GS: Livin promotes progression of breast cancer through induction of epithelial-mesenchymal transition and activation of AKT signaling. Cell Signal 25: 1413-1422, 2013.

16. Li X, Fan S, Li L, Wang L, Fan G, Zhao Q and Li Y: RNA interference-mediated knockdown of Livin suppresses cell proliferation and invasion and enhances the chemosensitivity to cisplatin in human osteosarcoma cells. Int J Oncol 43: 159-168, 2013.

17. Chen F, Yang D, Che X, Wang J, Li X, Zhang Z, Chen X and Song X: Livin mediates tumor cell invasion in the DU-145 cell line via NF-кB. Oncol Rep 27: 2010-2016, 2012.

18. Cho SB, Lee WS, Park YL, Kim N, Oh HH, Kim MY, Oak CY, Chung CY, Park HC, Kim JS, et al: Livin is associated with the invasive and oncogenic phenotypes of human hepatocellular carcinoma cells. Hepatol Res 45: 448-457, 2015.

19. Myung DS, Park YL, Chung CY, Park HC, Kim JS, Cho SB, Lee WS, Lee KH, Lee JH and Joo YE: Expression of Livin in colorectal cancer and its relationship to tumor cell behavior and prognosis. PLoS One 8: e73262, 2013.
20. Chen YS, Li HR, Lin M, Chen G, Xie BS, Xu NL and Lin LF: Livin abrogates apoptosis of SPC-A1 cell by regulating JNKI signaling pathway. Mol Biol Rep 37: 2241-2247, 2010.

21. Chen YS, Li HR, Miao Y, Chen WY, Li YT, Wang GQ and Wu ZC: Local injection of lentivirus-delivered livin shRNA suppresses lung adenocarcinoma growth by inducing a G0/G1 phase cell cycle arrest. Int J Clin Exp Pathol 5: 796-805, 2012.

22. Liu B, Han M, Wen JK and Wang L: Livin/ML-IAP as a new target for cancer treatment. Cancer Lett 250: 168-176, 2007.

23. Zhao X, Yuan Y, Zhang Z, Feng X, Zhang J, Yuan X and Li J: Effects of shRNA-silenced livin and survivin on lung cancer cell proliferation and apoptosis. J BUON 19: 757-762, 2014.

24. Nachmias B, Ashhab Y, Bucholtz V, Drize O, Kadouri L, Lotem M, Peretz T, Mandelboim O and Ben-Yehuda D: Caspasemediated cleavage converts Livin from an antiapoptotic to a proapoptotic factor: Implications for drug-resistant melanoma. Cancer Res 63: 6340-6349, 2003.

25. Abd-Elrahman I, Hershko K, Neuman T, Nachmias B, Perlman R and Ben-Yehuda D: The inhibitor of apoptosis protein Livin (ML-IAP) plays a dual role in tumorigenicity. Cancer Res 69: 5475-5480, 2009.

26. Shiloach T, Berens C, Danke C, Waiskopf O, Perlman R and Ben-Yehuda D: tLivin displays flexibility by promoting alternative cell death mechanisms. PLoS One 9: e101075, 2014.

27. Nachmias B, Lazar I, Elmalech M, Abed-El-Rahaman I, Asshab Y, Mandelboim O, Perlman R and Ben-Yehuda D: Subcellular localization determines the delicate balance between the anti- and pro-apoptotic activity of Livin. Apoptosis 12: $1129-1142,2007$

28. Kafri T, Blömer U, Peterson DA, Gage FH and Verma IM: Sustained expression of genes delivered directly into liver and muscle by lentiviral vectors. Nat Genet 17: 314-317, 1997.

29. Piacibello W, Bruno S, Sanavio F, Droetto S, Gunetti M, Ailles L, Santoni de Sio F, Viale A, Gammaitoni L, Lombardo A, et al: Lentiviral gene transfer and ex vivo expansion of human primitive stem cells capable of primary, secondary, and tertiary multilineage repopulation in NOD/SCID mice. Nonobese diabetic/ severe combined immunodeficient. Blood 100: 4391-4400, 2002.

30. Tabatabai G, Hasenbach K, Herrmann C, Maurer G, Möhle R Marini P, Grez M, Wick W and Weller M: Glioma tropism of lentivirally transduced hematopoietic progenitor cells. Int J Oncol 36: 1409-1417, 2010.

31. Goel HL and Mercurio AM: VEGF targets the tumour cell. Nat Rev Cancer 13: 871-882, 2013.

32. Lee S, Chen TT, Barber CL, Jordan MC, Murdock J, Desai S, Ferrara N, Nagy A, Roos KP and Iruela-Arispe ML: Autocrine VEGF signaling is required for vascular homeostasis. Cell 130: 691-703, 2007.

33. Overall CM and Kleifeld O: Tumour microenvironment opinion: Validating matrix metalloproteinases as drug targets and anti-targets for cancer therapy. Nat Rev Cancer 6: 227-239, 2006.

34. Overall CM and López-Otín C: Strategies for MMP inhibition in cancer: Innovations for the post-trial era. Nat Rev Cancer 2: 657-672, 2002.

35. Shiau AL, Teo ML, Chen SY, Wang CR, Hsieh JL, Chang MY, Chang CJ, Chao J, Chao L, Wu CL, et al: Inhibition of experimental lung metastasis by systemic lentiviral delivery of kallistatin. BMC Cancer 10: 245, 2010.

36. Liang Z, Yoon Y, Votaw J, Goodman MM, Williams L and Shim H: Silencing of CXCR4 blocks breast cancer metastasis. Cancer Res 65: 967-971, 2005.

37. Hartman ML and Czyz M: Anti-apoptotic proteins on guard of melanoma cell survival. Cancer Lett 331: 24-34, 2013

38. Rashidi B, Moossa AR and Hoffman RM: Specific route mapping visualized with GFP of single-file streaming contralateral and systemic metastasis of Lewis lung carcinoma cells beginning within hours of orthotopic implantation [correction of implantion]. J Cell Biochem 114: 1738-1743, 2013.

39. Yamamoto N, Tsuchiya $\mathrm{H}$ and Hoffman RM: Tumor imaging with multicolor fluorescent protein expression. Int J Clin Oncol 16: 84-91, 2011

40. Li X, Wang J, An Z, Yang M, Baranov E, Jiang P, Sun F, Moossa AR and Hoffman RM: Optically imageable metastatic model of human breast cancer. Clin Exp Metastasis 19: 347-350, 2002.

41. Li W, Li H, Li J, Wang H, Zhao H, Zhang L, Xia Y, Ye Z, Gao J, Dai J, et al: Self-assembled supramolecular nano vesicles for safe and highly efficient gene delivery to solid tumors. Int J Nanomed 7: 4661-4677, 2012. 
42. Cool SK, Breyne K, Meyer E, De Smedt SC and Sanders NN: Comparison of in vivo optical systems for bioluminescence and fluorescence imaging. J Fluoresc 23: 909-920, 2013.

43. Burrell-Saward H, Rodgers J, Bradley B, Croft SL and Ward TH: A sensitive and reproducible in vivo imaging mouse model for evaluation of drugs against late-stage human African trypanosomiasis. J Antimicrob Chemother 70: 510-517, 2015.
44. Liu HS, Jan MS, Chou CK, Chen PH and Ke NJ: Is green fluorescent protein toxic to the living cells? Biochem Biophys Res Commun 260: 712-717, 1999.

45. Ejeskär K, Fransson S, Zaibak F and Ioannou PA: Method for efficient transfection of in vitro-transcribed mRNA into SK-N-AS and HEK293 cells: Difference in the toxicity of nuclear EGFP compared to cytoplasmic EGFP. Int J Mol Med 17: 1011-1016, 2006 